\title{
Management of Chronic Pain Using Acupuncture as a Standalone Treatment - A Case Study
}

\author{
Hamad AlKahtani ${ }^{1}$ and J aleel Mohammed ${ }^{1,2 *}$ \\ ${ }^{1}$ Physical Therapy Department, King Faisal Specialist \\ Hospital and Research Centre, Riyadh, KSA \\ ${ }^{2}$ Rehabilitation Association for Hematopoietic Cell \\ Transplantation, Gloucester, UK \\ *Corresponding author: J aleel Mohammed, King \\ Faisal Specialist Hospital \& Research Centre, Kingdom of \\ Saudi Arabia
}

Received: December 14, 2020; Accepted: J anuary 06, 2021; Published: J anuary 13, 2021

\begin{abstract}
Background: Chronic pain is a suffering which patients endure due to various injuries or condition and has a significant impact on the overall quality of life. Where traditional medicine fails to bring the desired results for the patient, use of acupuncture to manage chronic pain has been reported to have beneficial results. The current case report aims to report the positive effects of acupuncture in managing chronic pain through presentation of a single case. The patient had a four-week PT Program, seen twice a week for acupuncture (Bilateral BL 23BL25, GV4, GV 3, and bilateral LI4). The main outcome measures used were visual analogue scale, Short Form 36 Health Survey (SF-36) and Oswesrty Low Back Disability Questionnaire. At the end of treatment, the patient had significant reduction in pain and improved outcomes thus supporting the use of acupuncture for pain management in chronic pain patients. The current case report affirms that acupuncture is both safe and effective in managing chronic pain and quality of life. Bilateral BL23, BL25, GV4, GV 3, and LI4 points used in the current case study has proven to be helpful in helping patient come off long-term pain medications.
\end{abstract}

Keywords: Acupuncture; Chronic pain; Fibromyalgia; Physiotherapy

\section{Introduction}

Reports of chronic pain, single site and/or multi-site are on the rise across the globe. In the Kingdom of Saudi Arabia (KSA) over $46 \%$ of the adult population has been reported as having chronic pain which is significantly higher when compared to the USA where $20.4 \%$ of adults reported as having chronic pain. Management of chronic pain requires a multidisciplinary approach, and Physical Therapist's (PT) plays an important role in improving function and quality of life. The use of acupuncture for pain management has widely been reported and PT's use various needling techniques to achieve the desired results. The effects from acupuncture have also been reported to have lasted for up to 12 months making it not only an efficient treatment technique but also a cost effective compared to some PT interventions.

The current case study reports one of those rare cases where acupuncture was used as a standalone treatment for managing patient's chronic pain, where other traditional PT intervention failed to produce the desired outcomes for the patient [1-9].

\section{Case Description}

A 30-year-old female nurse suffered Motor Vehicle Accident in 2015 and after which she developed generalized pain in the whole body, but predominantly in the lower back area. The patient reportedly had several physiotherapy sessions over the past 3 years and included therapeutic exercises, hydrotherapy, electrotherapy, manual therapy, and massage. Unfortunately, the patient did not gain any significant improvement in pain or functional capacity. The patient also underwent a course of painkillers (Acetaminophen and Tramadol) which reportedly helped keep her symptoms at bay from time to time. The patient did not report any underlying medical condition or family history of any diseases.

\section{Patient assessment}

The patient described her pain as a constant $6 / 10$ on daily basis which reduces to $4 / 10$ if on medications. On assessment the patient had normal gait pattern, intact dermatomes, myotomes and lower limbreflexes.

\section{Range of motion}

End range lumbar flexion pain, lumbar extension limited to 15 degrees due to pain, the lumbside rotation and flexion movement was within normal limits but again with end range pain. The patient also had full range of motion in her hips with no pain on movements.

\section{Special tests}

The hip and sacroiliac joint tests were negative, The raise was negative, the lumbar tests were negative too. No nerve root entrapment symptoms were reported during the tests.

Manual Muscle tests: 4+/5 in her upper and lower limbs.

\section{Palpation}

There was generalized muscle tenderness and tightness in her paraspinal muscles. No pain reported on the direct pressure on the facet joint area of the spine.

\section{Diagnostic tests}

Magnetic Resonance Imaging (MRI): Lumbar MRI, Minimal degenerative changes at lumbar spine L4/L5 and S1 level. No disc herniation, central stenosis or narrowing of the neural foramen.

$\mathrm{X}$-ray: Thoracolumbar $\mathrm{x}$-rays were also done which reported normal alignment of thoracolumb spine, the vertebral heights and intervertebral disc spaces well maintained and bilateral hip joints 
Table 1: SF36 Short (Pre and Post Treatment Scores).

\begin{tabular}{|l|c|c|}
\hline \multicolumn{1}{|c|}{ SF-36 Component } & $\begin{array}{c}\text { Score } \\
\text { (Pre-treatment) }\end{array}$ & $\begin{array}{c}\text { Score } \\
\text { (Post-treatment) }\end{array}$ \\
\hline Physical functioning: & $35 \%$ & $85 \%$ \\
\hline $\begin{array}{l}\text { Role limitations due to physical } \\
\text { health }\end{array}$ & $0 \%$ & $100 \%$ \\
\hline $\begin{array}{l}\text { Role limitations due to emotional } \\
\text { problems }\end{array}$ & $0 \%$ & $100 \%$ \\
\hline Energy/fatigue & $30 \%$ & $65 \%$ \\
\hline Emotional well-being & $48 \%$ & $72 \%$ \\
\hline Social functioning & $37.5 \%$ & $75 \%$ \\
\hline Pain & $22.5 \%$ & $77.5 \%$ \\
\hline General health & $15 \%$ & $60 \%$ \\
\hline Health change & $0 \%$ & $75 \%$ \\
\hline
\end{tabular}

were congruent.

\section{Outcome measures}

Visual analogue scale, Short Form 36 Health Survey (SF-36) and Oswestry Low Back Disability Questionnaire.

\section{Materials}

Single use sterilized acupuncture needles ( 2 sizes $40 \mathrm{~mm} \& 25 \mathrm{~mm}$ diameter)

\section{Intervention}

The acupuncture treatments were administered by a PT who was a certified acupuncture practitioner with over 3 years of experience. The patient was seen twice a week for four weeks and the acupuncture points used were bilateral BL 23BL25, GV4, GV 3, andLI4. Each session the needles were left for 30 minutes. The patient tolerated the sessions well with no signs of side effects and she also was compliant with the frequency of the sessions and duration [9-12].

\section{Results}

Over the course of 4 weeks the patient's pain on VAS reduced from 6 to 1, the Short Form 36 Health Survey (SF-36) score pre and post treatment is presented in the Table 1.

The patient also scored excellent on the Oswestry Low Back Disability Questionnaire from 26/50 pre-treatment to 5/50.

\section{Discussion}

Modern understanding of acupuncture is supported by the neurohormonal theory where the A-delta and $\mathrm{C}$ afferent nerve fibers are stimulated by inserting the needles in specific places on the body, thereby conveying signals to the central nervous system resulting in endogenous opioids production. Although there are some studies recommending the use of acupuncture for pain management, the literature is limited in providing information on specific points of acupuncture the management of whiplash related pain, particularly in such case where all other forms of interventions failed. In the current case study, we used Large Intestine 4 (LI4) point as it is believed to be a very powerful point and extremely effective in reducing pain and stress and boosting the immune system. L14 point has been used for various pain management including during the active phase of child delivery Bladder (BL) 24 and 25 points were used to target connective tissue plane within the erector spinae, between longissimus and iliocostalis. BL points have also shown to have a good pain relief effect and have been also used previously in managing post-operative pain. Lastly, Governor Vessels 3 and 4 (GV3 and GV4) were also used to help target the interspinous ligament and because it has been shown to yield good pain relief when treating musculoskeletal pain. The findings of this case study place light on different avenues and approaches for healthcare professionals in managing whiplash related back pain. Where the traditional medicine fails to provide sufficient pain management, acupuncture can help improve patient's quality of life by helping in pain management. Furthermore, considering the positive benefits from acupuncture and the proven safety record over the decades of practice, one might also opt for acupuncture as first line of treatment in view of avoiding long term side effects from pain medications. However, more research and high-quality trials are needed to identify the effects of selecting specific points and comparing points that are more local to the structures in managing chronic pain $[13,14]$.

\section{Conclusion}

Acupuncture is both safe and effective in managing chronic pain and quality of life. Bilateral BL23, BL25, GV4, GV 3, and LI4 points used in the current case study has proven to be helpful in helping patient come off long-term pain medications.

\section{References}

1. Gobina I, Villberg J, Valimaa R, Tynjala J, Whitehead R, Cosma A, et al. Prevalence of self-reported chronic pain among adolescents: Evidence from 42 countries and regions. European Journal of Pain. 2019; 23: 316-326.

2. Almalki MT, BinBaz SS, Alamri SS, Alghamdi HH, El-Kabbani AO, Al Mulhem $A A$, et al. Prevalence of chronic pain and high-impact chronic pain in Saudi Arabia. Saudi medical journal. 2019; 40: 1256.

3. Dahlhamer J, Lucas J, Zelaya C, Nahin R, Mackey S, DeBar L, et al. Prevalence of chronic pain and high-impact chronic pain among adultsUnited States, 2016. Morbidity and Mortality Weekly Report. 2018; 67: 1001.

4. Hall BH. Management of Chronic Pain: Nonpharmacological and Multidisciplinary Approach. In Evaluation and Management of Chronic Pain for Primary Care. Springer, Cham. 2020: 83-102.

5. Semmons J. The role of physiotherapy in the management of chronic pain. Anaesthesia\& Intensive Care Medicine. 2016; 17: 445-447.

6. MacPherson H, Vertosick EA, Foster NE, Lewith G, Linde K, Sherman KJ, et al. The persistence of the effects of acupuncture after a course of treatment: a meta-analysis of patients with chronic pain. Pain. 2017; 158: 784.

7. Ware JE, Sherbourne CD. The MOS 36-item short-form health survey (SF36): I. Conceptual framework and item selection. Medical care. 1992: 473483.

8. Fairbank JC, Couper J, Davies JB, O'brien JP. The Oswestry low back pain disability questionnaire. Physiotherapy. 1980; 66: 271-273.

9. Vander Ploeg K, Yi X. Acupuncture in modern society. Journal of acupuncture and meridian studies. 2009; 2: 26-33.

10. Haker E, Egekvist H, Bjerring P. Effect of sensory stimulation (acupuncture) on sympathetic and parasympathetic activities in healthy subjects. Journal of the autonomic nervous system. 2000; 79: 52-59.

11. Yildirim E, Alan S, Gokyildiz S. The effect of ice pressure applied on large intestinal 4 on the labor pain and labor process. Complementary therapies in clinical practice. 2018; 32: 25-31.

12. Sun Y, Gan TJ, Dubose JW, Habib AS. Acupuncture and related techniques for postoperative pain: a systematic review of randomized controlled trials. British journal of anaesthesia. 2008; 101: 151-160. 
13. Buckley RE. Use of acupuncture for musculoskeletal pain in an expedition medicine setting: a case series. Acupuncture in Medicine. 2018; 36: 425-427.

14. Mac Pherson H, Thomas K, Walters S, Fitter M. The York acupuncture safety study: prospective survey of 34000 treatments by traditional acupuncturists. Bmj. 2001; 323: 486-487. 